\title{
Vaginal breech delivery: survey of obstetricians in specialization in Cote d'Ivoire
}

\author{
Védi Louée ${ }^{1 *}$, N'drin Effoh ${ }^{2}$, Joachim Konan ${ }^{2}$, Eléonore Gbary $^{2}$, Christian Allah $^{2}$, \\ Raoul Kassé ${ }^{2}$, Soh Koffi ${ }^{2}$, Yao Abauleth ${ }^{2}$
}

\begin{abstract}
${ }^{1}$ Paris Descartes University, Sud Francilien Hospital Center (Woman-Mother-Child Pole), Paris, France
${ }^{2}$ Felix Houphouet-Boigny University, Faculty of Medical Sciences (Mother and Child Department, University Hospital of Cocody), Abidjan-Cote d'Ivoire
\end{abstract}

Received: 03 January 2016

Revised: 04 January 2016

Accepted: 06 February 2016

\section{*Correspondence:}

Dr. Védi Loué,

E-mail: drlouevedi@yahoo.fr

Copyright: ( $)$ the author(s), publisher and licensee Medip Academy. This is an open-access article distributed under the terms of the Creative Commons Attribution Non-Commercial License, which permits unrestricted non-commercial use, distribution, and reproduction in any medium, provided the original work is properly cited.

\begin{abstract}
Background: Vaginal breech delivery is becoming undeniably more unknown. The aim of this study is to contribute to its promotion in Sub-Saharan Africa.

Methods: This is a prospective survey of obstetricians in training on the vaginal breech delivery (VBD). The survey took place in gynecology and obstetrics services of the four university hospitals in Côte d'Ivoire from 2012 to 2015. One hundred and twelve (112) obstetricians in specialization were surveyed through an anonymous and individual questionnaire.

Results: The response rate was $93.75 \%$. A total of 38 physicians in specialization, or $36.2 \%$ had been able to achieve over ten VBD during their training. Obstetricians in specialization had received theoretical training on the VBD in $81 \%$ of cases and $45.7 \%$ were receiving practical training. Only $58.1 \%$ had a good theoretical knowledge of VBD specific complications and $41 \%$ had a good knowledge of obstetric maneuvers. Of the 105 physicians who responded, $38.1 \%$ reported having practical mastery of the VBD which was influenced by the type of responsibility entrusted to doctors during their training $(\mathrm{p}<0.000)$. After specialization, 37 physicians $(35.2 \%)$ reported accept the programming of VBD and this choice as first line was significantly influenced by the level of practical mastery of the VBD $(\mathrm{p}<0.000)$.

Conclusions: The results of this study prove undeniably that future obstetricians have a theoretical and practical knowledge insufficient in vaginal breech delivery. This finding requires a necessary promotion of VBD preceded by a very good formation in obstetrics.
\end{abstract}

Keywords: Survey, Breech vaginal delivery, Obstetricians in training, Cote d'Ivoire

\section{INTRODUCTION}

After 2000, the result of publications in favor of systematic cesarean section in breech delivery was immediate and many countries' caesarean rate has increased of 4 to 8 points in 10 years up to $80 \%$ in some countries. ${ }^{1-3}$ However there is no real consensus on the breech delivery modality because some studies are in favor of vaginal delivery subject to compliance with strict selection criteria and under the supervision of an experienced obstetrician.,

In sub-Saharan black Africa where the rate of unscarred uterine rupture is already very high, a systematic policy 
of planned caesarean section for breech presentation at term will participate in the increase of scarred uterus and also the increase of obstetric morbidity that result. ${ }^{6}$ In reality it cannot allow in our context as undermedicalization, impoverishment and illiteracy, prevent the occurrence of a sudden very common vaginal breech delivery (VBD).

The aim of this study was to contribute to promoting the control of vaginal delivery of fetus at term in breech presentation. The specific objectives are to:

- Specify the level of theoretical and practical knowledge of obstetricians in specialization in vaginal breech delivery.

- Identify the quality of formation received by learners.

- Identify the place of vaginal breech delivery among physicians after their specialization.

\section{METHODS}

We conducted a prospective survey of physicians in obstetrics gynecology specialization in Cote d'Ivoire on VBD of a single fetus in breech presentation at term (at least 37 weeks of amenorrhea). One hundred and twelve (112) physicians at the end of their training ( $4^{\text {th }}$ year of specialized study in obstetrics and gynecology) from four successive generations (2012, 2013, 2014 and 2015) were surveyed every time they arrived in the fourth year of their formation.

The survey took place in gynecology and obstetrics services of the four university hospitals of Côte d'Ivoire from 2012 to 2015 in August of above mentioned years, just before the end of the academic year. The specialized diploma in gynecology obstetrics (SDGO) in our country is done in four years after the doctorate and after admission to the pre selection contest. The SDGO is obtained by $4^{\text {th }}$ year after a written exam, a practical assessment and a memory.

A survey sheet, individual and anonymous, was developed and tested in advance on some physicians to assess the understanding of issues and the quality of responses. Then according to the first answers the survey sheet was secondarily improved.

In each university hospital, after the authorization of the head of service, the sheet was given to each obstetrician in training after a brief explication.

The questionnaire focused on the following components:

- The general characteristics of the surveyed physicians: the number of breech vaginal deliveries made along their formation, the average number of guards carried monthly and the status or not of head guard.
- The theoretical knowledge of VBD specific complications and their various obstetric maneuvers those are required.

- The conduct of teaching in which we include theoretical and practical teaching on obstetric maneuvers during breech delivery.

- The impact of the teachings concerning particular practical mastery of VBD obstetric maneuvers.

- And finally we asked the learners of their choice concerning the mode of breech presentation delivery at term after their specialization.

For this study we have included physicians in specialization regularly enrolled in a $4^{\text {th }}$ year of SDGO and who were actually present on the internship sites.

Data were collected year by year and statistical analysis of the studied variables was compared using the Chisquare test and Fisher's exact test, the result being significant for $\mathrm{p}<5 \%$.

\section{RESULTS}

\section{Characteristics of physicians in specialization}

- From 2012 to 2015 , there have been 112 physicians registered in $4^{\text {th }}$ year of obstetrics and gynecology specialization in Côte d'Ivoire or 28 physicians per year. Among the 112 physicians surveyed, 105 have correctly filled our survey sheet. The response rate was $93.75 \%$. We would take into account that the 105 physicians for the remainder of the study.

- In a Table 1 is summarized the other characteristics of physicians in training.

Table 1: Guards performed per month and total of VBD performed along the course.

\begin{tabular}{|llll|ll|}
\hline Guards & \multicolumn{2}{l}{ Total } & Number of & \multicolumn{2}{|c|}{ Total } \\
per month & n & $\%$ & VBD & n & $\%$ \\
\hline$<4$ & 10 & 9.5 & $<5$ & 32 & 30.5 \\
\hline$(4-6)$ & 60 & 57.2 & $(5-10)$ & 35 & 33.3 \\
\hline$>6$ & 35 & 33.3 & $>10$ & 38 & 36.2 \\
\hline Total & 105 & 100 & Total & 105 & 100 \\
\hline
\end{tabular}

The physicians made an average of four to six guards monthly in $57.2 \%$ of cases and in $33.3 \%$ of cases over six guards per month. Among of the 105 physicians, 36.2\% $(n=38)$ had achieved more than ten VBD during their training.

\section{Theoretical and practical teaching of physicians on VBD}

The vast majority of physicians (81\%) had received theoretical training on the VBD while $45.7 \%$ were receiving practical training (Table 2 ). 
Table 2: Responses of physicians according to theoretical and practical training received.

\begin{tabular}{|lll|}
\hline & \multicolumn{2}{l}{ Total } \\
\hline Theoretical training & n & $\%$ \\
Yes & & \\
No & 85 & 81 \\
\hline Total & 20 & 19 \\
\hline Practical training & 105 & 100 \\
\hline Yes & & \\
No & 48 & 45.7 \\
\hline Total & 57 & 54.3 \\
\hline
\end{tabular}

\section{Impact of the teachings received}

- The impact of the teachings received by physicians translates the theoretical and practical knowledge on VBD. Physicians in $58.1 \%$ of cases had a good theoretical knowledge of VBD specific complications and $41 \%$ had a good knowledge of obstetric maneuvers. Of the 105 physicians who responded, $38.1 \%(n=40)$ reported having practical mastery of the VBD.

- Regarding the level of responsibility entrusted to learners during their training, chief of guards had more practical mastery of the VBD than those who have never been head $(58.3 \%$ versus $11.1 \%$; $\mathrm{p}<0.000$ ) (Table 4).

Table 3: Theoretical knowledge specific to VBD (theoretical descriptions).

\begin{tabular}{|lll|}
\hline Theoretical knowledge & $\begin{array}{l}\text { Total } \\
\text { n }\end{array}$ & $\%$ \\
\hline Specific complications & & \\
Yes & 61 & 58.1 \\
No & 44 & 41.9 \\
\hline Total & 105 & 100 \\
\hline Obstetric maneuvers & & \\
Yes & 43 & 41 \\
No & 62 & 59 \\
\hline Total & 105 & 100 \\
\hline
\end{tabular}

Table 4: Influence of the VBD control on the future choice of breech delivery route.

\begin{tabular}{|c|c|c|c|c|c|c|}
\hline & \multicolumn{2}{|c|}{$\begin{array}{l}\text { VBD } \\
\text { mastery }\end{array}$} & \multicolumn{2}{|c|}{$\begin{array}{l}\text { VBD non- } \\
\text { mastery }\end{array}$} & \multicolumn{2}{|c|}{ Total } \\
\hline & n & $\%$ & n & $\%$ & & $\%$ \\
\hline Attempt VBD & 18 & 45 & 19 & 29.2 & 37 & 35.2 \\
\hline $\begin{array}{l}\text { Systematic } \\
\text { cesarean }\end{array}$ & 22 & 55 & 46 & 70.8 & 68 & 64.8 \\
\hline Total & 40 & 100 & 65 & 100 & 105 & 100 \\
\hline
\end{tabular}

\section{Future choice of breech delivery mode}

Of the 105 physicians surveyed, 37 (35.2\%) reported accept the programming of the VBD as a future option.
More they had mastered the practice of VBD; the more they opted for a vaginal attempted first-line (45\% versus $29.2 \%, \mathrm{p}<0.000)$ (Table 5).

Table 5: Influence of the responsibility on the VBD control.

\begin{tabular}{|lccccccc|}
\hline & \multicolumn{2}{c}{ Team head } \\
& n & $\%$ & \multicolumn{2}{c|}{ Non-team head } & \multicolumn{2}{c|}{ Total } \\
n & $\%$ & n & $\%$ \\
\hline $\begin{array}{l}\text { VBD } \\
\text { mastery }\end{array}$ & 35 & 58.3 & 5 & 11.1 & 40 & 38.1 \\
\hline $\begin{array}{l}\text { VBD } \\
\text { non-mastery }\end{array}$ & 25 & 41.7 & 40 & 88.9 & 65 & 61.9 \\
\hline Total & 60 & 100 & 45 & 100 & 105 & 100 \\
\hline
\end{tabular}

\section{DISCUSSION}

\section{General characteristics of physicians in specialization}

During the study period, 112 physicians in obstetrics gynecology specialization in Cote d'Ivoire were in fourth year. The response rate to the questionnaire was $93.75 \%$. Similar studies reported responses rates of $65 \%$ and $45.5 \% .^{7,8}$

Childbirth of a fetus at term in breech presentation per vaginal route is a distressing situation for the obstetrical team; on the one hand because of its "potentially obstructed" character and secondly because of morbidity and perinatal mortality 4 times higher than that of the general population. Despite the acceptance criteria of the vaginal route developed in 1994 by FIGO, the breech vaginal delivery tends to disappear so that young obstetricians today do not keep a real experience. ${ }^{5}$ This is illustrated in the study of Gratius in France in 2000, where $41.6 \%$ of internal in obstetrics and gynecology specialization had never achieved a vaginal breech delivery. $^{8}$

The publications favorable to the systematic cesarean ${ }^{2}$ in the breech presentation have led to a fall in the percentage of vaginal delivery from $50 \%$ to $20 \%$ in some countries. $^{9}$

In countries like ours, where the systematic practice of elective caesarean section is not feasible, it remains imperative that our obstetricians in specialization continue to have quality training especially in the VBD as experience and competence is a key point in the management of term fetuses in breech presentation.

In this study, only $57.2 \%$ of doctors in specialization said performing on average 4 to 6 guards per month. However it is not always a real relationship between the number of guards performed per month and the number of VBD achieved during their training by virtue of the relative scarcity of breech presentation. Indeed only $36.2 \%$ of physicians in obstetrics gynecology specialization in this study had completed over 10 VBD. 
Although the decrease in the practice of obstetrics gesture compromise training and obstetricians practice, it is very difficult to set a threshold number of VBD from which we can estimate that a physician in specialization acquired sufficient experience for his practical training. ${ }^{8}$

During their formation for SDGO in Ivory Coast, this training that is in full reformulation; it is recommended that the physician must have made at least 50 normal births, 20 instrumental extractions and 10 breech vaginal deliveries. The European Board and College of Obstetrics and Gynecology (EBCOG) consider that an internal in obstetrics and gynecology must have performed at least 100 normal births and 40 assisted deliveries including instrumental extractions and VBD. ${ }^{8}$ In the National College of French Obstetricians Gynecologists (CNGOF) through the internal booklet, recommends internal to achieve at least 50 deliveries, including breech presentations and twin pregnancies, 40 instrumental extractions and 40 Caesarean sections. ${ }^{10}$

VBD is very delicate, it is clear that achieving only a few deliveries can enable mastery of this practice. In this study, $63.8 \%$ of physicians in specialization realized within $10 \mathrm{VBD}$ in four years training. Recognizing this, the practical experience of physicians in training in Cote d'Ivoire, which is probably true, seems very insufficient and this generates a real concern especially in an underequipped country where the waiting delay performing an emergency Caesarean section can easily reach three hours. 6

\section{Theoretical and practical teaching on vaginal breech delivery}

We conducted a survey in which $81 \%$ of physicians (Table 2) reported having received theoretical instruction on VBD. The impact of this theoretical formation is not real because only respectively $58.1 \%$ and $41 \%$ of physicians in training could theoretically describe the specific complications of VBD and obstetric maneuvers applied to them (Table 3 ). In contrast, $45.7 \%$ of learners have benefited from practical training on obstetric maneuvers applied to breech delivery or during vaginal delivery or during cesarean sections.

The abandonment of doctors in specialization by seniors, the lack of real will of learners and the lack of adequate training materials such as simulation models of obstetric maneuvers in our various structures involved in this low level of practical training. But the tutorial system in the reformulation of the SDGO and the current re-equipment of our hospitals give a glimmer of hope.

The use of simulation models has been reported to be particularly effective for the acquisition of obstetric maneuvers such as the reduction of a shoulder dystocia or maneuvers on fetus in breech presentation. ${ }^{11,12}$ While all of the university hospitals in developed countries have simulation models, the situation of the theoretical training of French internal in gynecology and obstetrics at the VBD does not seem to change. ${ }^{8}$ Indeed, $41.6 \%$ of French internal said they had never received any theoretical teaching on VBD, proof that the models made available to the internal are underused, the majority of internal not even be aware of their existence. ${ }^{8}$

Theoretical and practical teaching of quality should lead to experienced obstetricians and particularly in controlling the practice of VBD. In our study, only 40 physicians in specialization or $38.2 \%$ reported having practical mastery of the VBD. This control of VBD rate was also influenced by the level of responsibility entrusted to doctors in training $(p=0.000)$. In the study of Chinnock, $53 \%$ of interns last year, felt confident in achieving a breech vaginal delivery. ${ }^{7}$

\section{Future choice of breech delivery mode}

There is no consensus on the modalities of delivery of fetus in breech presentation at term in our hospitals, as in the literature. Only $35.6 \%$ of surveyed physicians responded achieve for the future planned breech vaginal delivery first line without any mandatory prophylactic indication of cesarean section. More they had mastered the practice of BVD, the more they opted for a vaginal attempted first-line ( $p<0.000)$. In the study of Gratius, a large majority of interns says to be ready to consider practice of programmed VBD in their future practice. ${ }^{8}$ Conversely, about 53\% of Australian interns who responded control $\mathrm{VBD}$, only $11 \%$ were planning to practice programmed VBD in their future. ${ }^{11}$ Thus to date the opinions are still divided on the modalities of delivery of fetus in breech presentation at term.

In our context, it is important that the next generation of African obstetricians is prepared for active management of an unexpected breech delivery. The mastery of VBD undeniably participates in reducing scar uterus whose management is difficult here, hence its necessary promotion.

\section{CONCLUSION}

This study proves that future obstetricians have an insufficient level of theoretical and practical training. Africa would hardly bear the consequences of a systematic policy of caesarean section for breech presentation. This sad fact requires that necessary promotion of breech vaginal delivery be advocated and preceded by proper training of obstetricians and adequate equipment for the training of doctors in specialization.

Funding: No funding sources

Conflict of interest: None declared

Ethical approval: The study was approved by the Institutional Ethics Committee 


\section{REFERENCES}

1. Gupta E, Nulakanta D, Dwarakanah LS, Gee H. Planned vaginal delivery versus elective cesarean section a study of 705 singleton term breech presentations. BJOG. 2000;107(8): 1058.

2. Hanna ME, Hannah WJ, Hewson SA, Hodnett ED, Saigal S, Willan AR. Term Breech Trial Collaborative Group. Planned caesarean section versus planned vaginal birth for breech presentation at term: A randomized multicentre trial. Lancet. 2000;356:1375-83.

3. Hannah ME, Hannah WJ, Hodnett ED, Chalmers B, Kung R, Willan A. Outcomes at 3 months after planned cesarean vs planned vaginal delivery for breech presentation at term: The International randomized Term Breech Trial. Jama. 2002;287:1822-31.

4. Caroyal M, Blondel B, Zeitlin J, Breart G, Goffinet F. Changes in the rates of caesarean delivery before labour for breech presentation at term in France: 1972-2003. Eur J Obstet Gynecol Reprod Biol. 2007;132:20-6.

5. FIGO. Recommendations of FIGO on perinatal health on guidelines for the management of breech delivery. Int J Gynecol Obstet. 1994;44(3):297-300.

6. Loue VA, Jean MD, Effoh DN, Adjoby RC, Konan KJ, Gbary EA, et al. Management and prognosis of uterine rupture during labor in an under-medicalized country: about 513 cases collected at the Cocody
University Hospital Center (Abidjan-Cote d'Ivoire). Int J Reprod Contracept Obstet Gynecol. 2015;4(5):1277-82.

7. Chinnock M, Robson S. Obstetrics trainees' experience in vaginal breech delivery implications for future practice. Obstet Gynaecol. 2007;110:9003.

8. Gratius E, Bourgain A, Carcopino X. Accouchement par le siège : l'expérience des stagiaires français en gynécologie obstétrique. J Gynécol Obstet Biol Reprod. 2010;39(2):144-50.

9. Boulvain M. Pratique de la césarienne. Evolution des taux et des indications de césarienne. J Gynecol Obstet Biol Reprod. 2008;37:2-3.

10. CNGOF, Agof. Livret de l'interne en gynécologieobstétrique. 2008.

11. Carcopino X, Bats A. Number of training positions in obstetrics and gynecology in France: Results from a national survey of trainees. J Gynecol Obstet Biol Reprod. 2005;34:463-72.

12. Carcopino X, Bats AS. What about fellowship for French residents in obstetrics and gynecology? J Gynecol Obstet Biol Reprod. 2006;35:242-6.

Cite this article as: Loué V, Effoh N, Konan J, Gbary E, Allah C, Kassé R, et al. Vaginal breech delivery: survey of obstetricians in specialization in Cote d'Ivoire. Int J Reprod Contracept Obstet Gynecol 2016;5:651-5. 